\title{
Morphometric Data of Testudo hermanni in the Vlora
}

\section{Area}

\author{
Hajdar Kicaj ${ }^{1}$, Enerit Saçdanaku ${ }^{2}$ and Berlinda Shkurtaj ${ }^{1}$ \\ 1 Department of Biology, Universitety "Ismail Qemali" Vlore, Vlora 9400, Albania \\ 2 Museum of Natyral Science, Universitety of Tirana, Tirana 1000, Albania
}

\begin{abstract}
The purpose of this paper is the morphometric study as well as the assessment of population structure of the Testudo hermani tortoise in the Vlora area. Individuals are collected in the study area. A morphometric study is made for the caught individuals. Suitable habitats have been identified for their growth and development. It is estimated the number of healthy or unhealthy individuals, dead individuals and also the identification of the local population's threatening factors. Individuals with anomalies are studied and then compared with normal individuals, especially in terms of the number and shape of the dermal plates.
\end{abstract}

Key words: Testudo hermanni, morphometric study, population structure, habitat.

\section{Introduction}

Mediterranean has been an important area of research for many biological aspects of Testudo tortoise genus and especially Testudo hermanni. The search has been mainly concentrated in the [1] variety, [2] ecology, sexual dimorfism and morphological variation of [3]). Systematic status of the Testudo hermanni tortoise has been disputed by various writers. Testudo hermanni is assigned in the Eurotestudo tortoise by many authors $[4,5]$, while others have moved the Mediterranean forms Testudo hermanni hermanni, and the Balkans' Testudo hermanni boettgeri at the level of species and have recognized Dalmatian populations as third species, Testudo hercegovinensis [6]. Testudo hermanni is a sub-specie with a limited habitat. They are found in agricultural country areas, grassy areas, pastures, areas with sparse vegetation, always close to forest habitats. Populations are dwindling rapidly, a trend which is thought that will continue in the future. This decrease is noted mostly by habitat loss. The main threats to the Testudo hermanni tortoise come from increased frequency of

Corresponding author: Hajdar Kicaj, Ph.D., professor, research field: zoology and ekology. fires, droughts, extreme temperatures, climate change etc. Testudo hermanni is considered species with threatened status [7], and in danger of extinction [8].

\section{Materials and Methods}

The research area is a part of Vlora Region. Landfills are determined in advance, based on climatic conditions, vegetation, other representative features of the area, such as height above the sea level, the vegetation presence, soil types etc. The study was done in Vlora region during 2015-2016. Data collection was done in four collection stations: Kanina, Dukat, Llogara, Vranisht. During the outreach, all the potential individuals have been identified in the whole area of study. For each gathered individual morphometric measurements were performed and the data are cast in a standard form. Data collection methodologies are based on the published work by local and foreign authors [9]. Each individual was marked with a unique code by sawing a piece of tortoise shell.

Tortoises were captured by hand, measured, marked with a permanent line and then released in the exact capture area. For the analysis of biometric elements, dead animals from natural causes were also analyzed. 


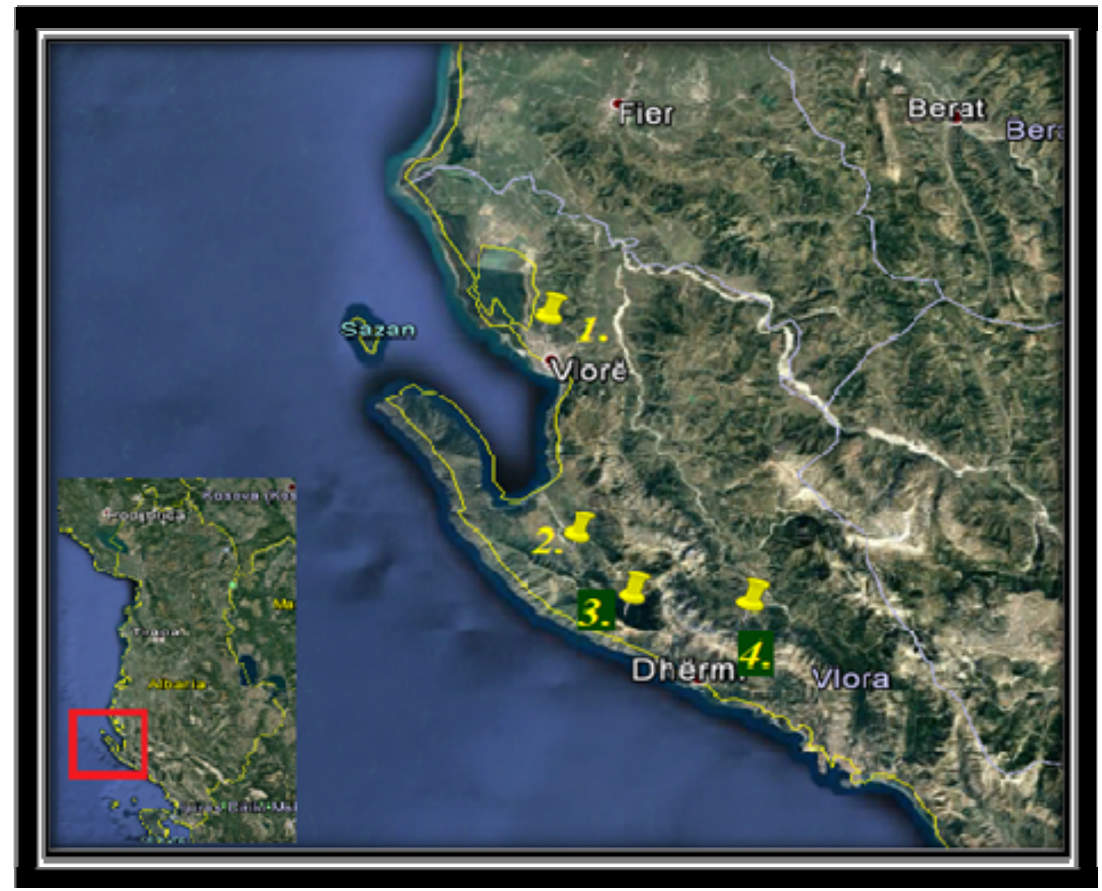

Fig. 1 View from the studied area.

Gender was determined on the basis of external characteristics. They were distinguished by external shape of the skeleton, the shape of the rear lateral scute, width at anal and supracaudal level, shape and size of the tail $[3,10,11]$. Adult animals are considered as $13 \mathrm{~cm}$ in size for males and over $15 \mathrm{~cm}$ for females [10]. For this it is measured the carapace length-SCL. Tortoises smaller than $13 \mathrm{~cm}$ are considered juvenile [9].

The morphometric datas for each individual are cast in a standard table. The marked type of habitat where the individual was found; oak forest, pine, shrub, herbaceous etc. Simple tailoring meter and a scaled ruler are used for measurements. An electronic scales is used for the weight.

\section{Results and Discussion}

81 individuals were studied from which, 75 alive individuals and 6 dead individuals. Morphometric data are analyzed for 28 individuals males and 47 females. Of the individuals captured, three are considered juvenile and three of them represent anomalies in shape or number of carapace plates. Morphometric data for the all studied individuals are presented in Excel tables where the processing of data is made. Length/width carapace ratio starts from 0.977-1.105 for females and 1.005-1008 for males, against their respective average reports 1.033 for females and 1.044 for males. Testudo hermanni tortoises are sexually demorfic in body size and shape [12]. Female gender was the greatest in the general population. Males are smaller than females. Males have a long tail (about 1/4 the length of the carapace comparing to $1 / 6$ at females). The tail also is thicker at the base, suprcaudal scutis is curved and the back of plastron has a wider opening than in female individuals. The plastron is concave, wide and long tail, wide anal hole. The shell forms of men, especially carapace, is trapezoidal, while in females is approximately oval. The large marginal bottom plate of males is often curved down. The shell form of females is simpler: the lower part of the carapace is narrower than the middle of the shell and the marginal plate almost touches the ground [10]. Changes in the shape and construction of the shell are noticed, and do not appear equally in both genders. These unusual final details 
are: noticeable lump on the back of the shell in males; in some cases the bending of the supracaudal element also in males.

\subsection{Morphological Abnormalities in Samples of Testudo hermanni}

Morphological abnormalities are observed in the studied individuals of Testudo hermanni boettgeri. According to external morphological characteristics, three morphologically abnormal individuals were observed. This has to do with the vertebrae dermal forms of plates. In an individual plate forms of vertebral V3, V4 and V5 are not normal. Another sixth plate was also found, differently from normal individuals.

\subsection{Life Cycle}

Testudo hermanni tortoise has an annual life cycle divided into two parts: the hibernation period (November-March/April) and the active period (March/April-November). During the period of hibernation, there may be interruptions when temperatures are extremely high. In our first study Testudo hermani tortoise was caught on 04/04/2016 in the Orikum area; on 04/10/2016 in the Vranishti area.

\subsection{Prefered Habitat}

Habitat types and habitat physical characteristics: location, geomorphology, geology and climate parameters [13]. Testudo hermanni prefer soft ground habitats and forest habitats. Forests are a main habitat for tortoises. Almost half of them were found near broadleaved forests and mixed forests. The habitat can be characterized as a transitional habitat between a scrub forest followed by herbaceous vegetation areas. The presence of a tortoise on a ground cover or another is the validity function of another near habitat. So if tortoises are found in agricultural areas, grassy areas, pastures or areas with low vegetation, forests will always be near these habitats. Females build their nests in the woods, which keeps the eggs away from

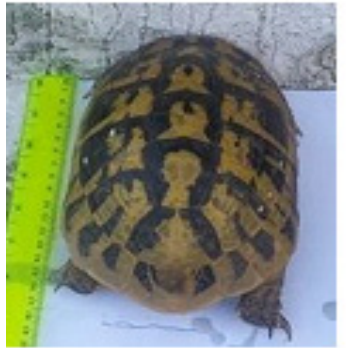

a

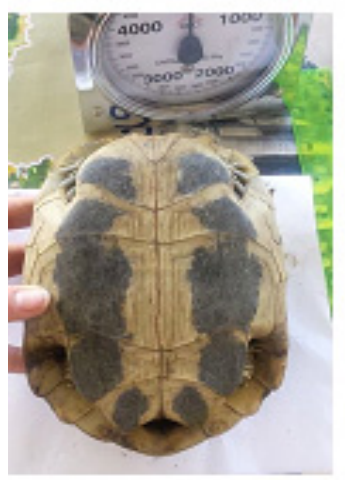

C

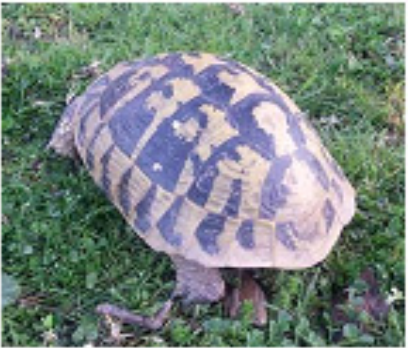

b

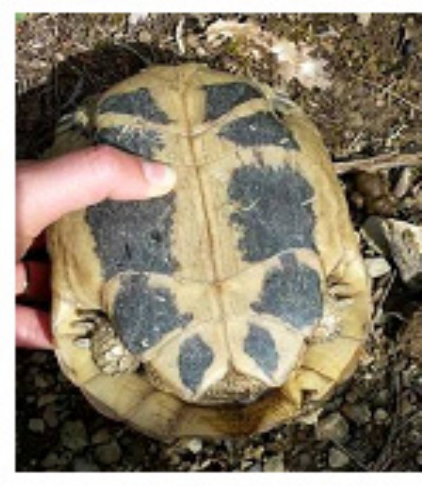

d
Fig. 2 Photo of Testudo hermanni; The difference between males $(a, c)$ and females $(b, d)$ : (a, b) shape of suprcaudal scutis, (c, d) angle of anal scutis and the plastron shape.
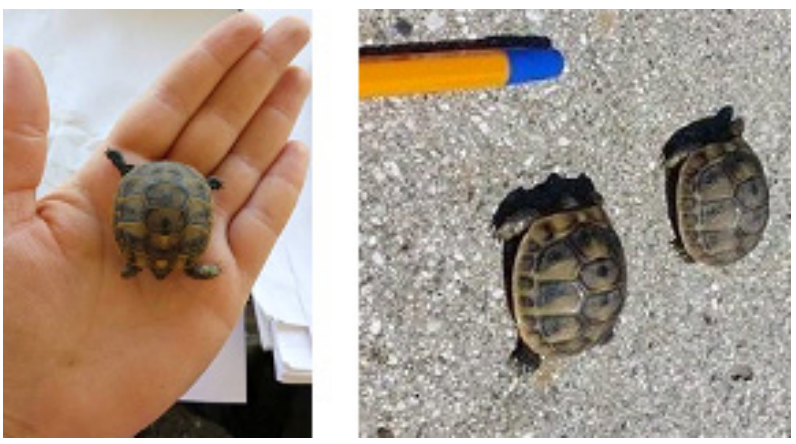

Fig. 3 Photo of juvenil individuals.

predators. Due to the destruction of habitats they are also found in dry, hilly or farmland soils. Despite not being optimal, these habitats are adapted for tortoises if vegetation is present.

\subsection{The population structure}

Young ones are defined all male individuals below $10 \mathrm{~cm}$ (this size is generally reached for about 6-8 years) and all female individuals smaller than $15 \mathrm{~cm}$. The very small number of juvenile individuals can be taken as an indication of the endangered population $[14,15]$. 

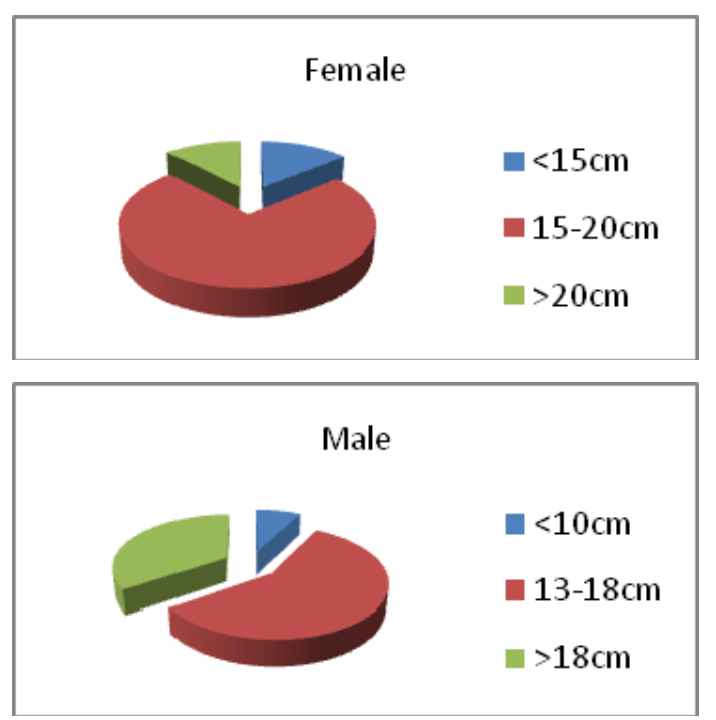

Fig. 4 Populatin structure of Testudo hermanni, according to length-SCL, in males and females.

From the charts above, adult individuals appear to predominate. Young individuals that are found have a small percentage in this population. This fact can affect, in the future, an endangering of the population, but the fact that the juvenile individuals often remain hidden must be taken into consideration. Based on the statistics the ratio between males and females (sex-ratio) in the tortoise population of the studied area is $1: 1.67$. By analyzing the data above, we can conclude that sex-ratio as a demographic factor in the case of the studied population, has no practical impact that can negatively affect the population reduction. Other factors, which may be from biotic or abiotic nature can affect the population risk and reduction. The identified current threats are: loss of habitat, accidental death, natural disasters, internal factors and human activity. Habitat loss from various factors contributes the most in the reduction of the tortoise population.

\section{Conclusions}

In this paper 75 Testudo hermani living individuals were studied. They were captured, measured biometricly and released in the capture site. Also part of this study includes data for six dead individuals from various causes, three of which, juvenile individuals.

Results from biometric measurements show that $37 \%$ of individuals are males and $63 \%$ females. Only $13 \%$ of these are juvenile specimens. The small number of juvenile individuals should be taken as a concern for the population.

Sexual dimorfism is quite evident at Testudo hermani. Elements taken into consideration include CCL, SCL, CCW, PL, PW, TL, height, weight, etc.

The main threats to Testudo hermanni tortoises: habitat loss and erosion, accidental death, pollution, natural disasters, internal factors, human activity.

\section{References}

[1] Fritz, U., and Havas, P. 2007. "Checklist of the chelonians of the world." Vertebrate Zoòlogy, Dresden 57: 149-368.

[2] Meek, R., and Inskeep, R. 1981. "Aspects of the field biology of a population of Hermanns tortoise (Testudo hermanni) in southern Yugoslavia." British Journal of Herpetology 6: 159-64.

[3] Djordjević, S., Tomović, L., Golubović, A., Simović, A., Sterijovski, B., Djurakić, M., and Bonnet, X. 2013. "Geographic (in) variability of Gender-specific traits in Hermann's tortoise." Herpetological Journal 23: 67-74.

[4] Lapparent De Broin, F., Bour, R., Pharham, J. F., and Perala, J. 2006. Eurotestudo. A new genus for the species Testudo hermanni GMELIN, 1789-Comptes Palevol, Paris, 5: 803-11.

[5] Lapparent De Broin , F., Bour, R., Pharham, J. F., and Perala, J. 2006b. Morphological definition of Eurotestudo (Testudinidae, Chelonii): First-Annales Paleontologiques, Paris, 92: 385-386.

[6] Perälä, J. 2004. "Testudo hercegovinensis Werner, 1899." Manouria 7 (22): 19-20.

[7] Cheylan, M. 2001. Testudo hermanni Gmelin, 1789-Griechische Landschildkröte, pp. 179-289. In: Schildkröten (Testudines) I (Bataguridae, Testudinidae, Emydidae). (Fritz, U. ed.), ser. Handbuch der Reptilien und Amphibien Europas., vol 3/IIIA, Aula-Verlag, Wiesbaden.

[8] Cox, N. A., and Temple, H. J. 2009. European Red List of Reptiles. Luxembourg: Office for Official Publications of the European Communities, Cambridge Publishers.

[9] Stubbs, D., Hailey, A., Pulford, E., and Tyler, W. 1984. "Population ecology of European tortoises: Review of field techniques." Amphibia-Reptilia 5: 57-68. 
[10] Willemsen, R. E., and Hailey, A. 2003. "Sexual dimorphism of body size and shell shape in European tortoises." Journal of Zoology 260: 353-65.

[11] Djordjević, S., Djurakić, M., Golubović, A., Ajtić, R, Tomović, L., and Bonnet, X. 2011. "Sexual body size and body shape dimorphism of Testudo hermanni in central and eastern Serbia." Amphibi-Reptilia 32: 445-458.

[12] Kozlowski, J. 1982. "Sexual size dimorphisn: a life history perspective." Oikos 54: 253-5.

[13] Donită, N., Popescu, A., Păucă-Comănescu, M., Mihăilescu, S., and Biris, I. A. 2005.

[14] IUCN 2001. IUCN Red List Categories and Criteria: Version 3.1. IUNCN. Gland, Switzerland and Cambridge.

[15] IUCN 2003. Guidelines for Application of IUCN Red Lines Criteria at Regional Levels: Version 3.0. IUCN Species Survival Commission. Gland, Switzerland and Cambridge. 